\title{
Exponential Stability of Cohen-Grossberg Neural Networks with Impulse Time Window
}

\author{
Mei Liu, Haijun Jiang, and Cheng Hu \\ College of Mathematics and System Sciences, Xinjiang University, Urumqi, Xinjiang 830046, China \\ Correspondence should be addressed to Haijun Jiang; jianghaijunxju@163.com
}

Received 29 March 2016; Accepted 19 May 2016

Academic Editor: Zhengqiu Zhang

Copyright (C) 2016 Mei Liu et al. This is an open access article distributed under the Creative Commons Attribution License, which permits unrestricted use, distribution, and reproduction in any medium, provided the original work is properly cited.

\begin{abstract}
This paper concerns the problem of exponential stability for a class of Cohen-Grossberg neural networks with impulse time window and time-varying delays. In our letter, the impulsive effects we considered can stochastically occur at a definitive time window and the impulsive controllers we considered can be nonlinear and even rely on the states of all the neurons. Hence, the impulses here can be more applicable and more general. By utilizing Lyapunov functional theory, inequality technique, and the analysis method, we obtain some novel and effective exponential stability criteria for the Cohen-Grossberg neural networks. These results generalize a few previous known results and numerical simulations are given to show the effectiveness of the derived results.
\end{abstract}

\section{Introduction}

Cohen-Grossberg neural network, which was first proposed by Cohen and Grossberg in 1983 [1], is one of the most typical and popular neural network models because it contains some well-known neural networks such as recurrent neural network, cellular neural network, and Hopfield neural network as a special case. Recently, the studies of Cohen-Grossberg neural networks are many since Cohen-Grossberg neural networks have been widely applied to various problems arising in scientific and engineering areas, such as optimization problem, system control, signal processing, associative memory, pattern recognition, and new class of artificial neural network.

Time delays, in implementation of neural networks, are inevitably encountered in the signal transmission attribute to the finite switching speed of amplifiers. Moreover, besides delay influence, it has been observed that many a physical system may suffer instantaneous perturbations which may exhibit impulsive effects. So, the control of impulsive neural networks with delays is of both theoretical significance and practical significance. In recent years, neural networks with delays and impulse have been extensively investigated by a large quantity of researchers [2-4]. Global exponential stability of Cohen-Grossberg neural systems with time-varying delays via impulsive control was investigated in [2]. Existence and exponential stability of periodic solution for shunting inhibitory cellular neural networks with impulses and delay were considered in [3]. Exponential stability of fuzzy CohenGrossberg networks with impulsive effects and time delays were introduced in [4].

Under the current situation, in order to stabilize or synchronize nonlinear dynamical systems, impulsive control strategy, as an important control means, has been widely concerned. From the control point of view, impulsive control theory has extensive applications; for example, it can be applied in HIV prevention model [5], pest control model [6], and nanoelectronics [7]. Thus, it is necessary to investigate the stability of nonlinear system based on the impulsive control.

In the past decades, the analysis for impulsive systems has attracted attention widely [8-10]. But in the existing literatures of impulsive control [11-13], the impulsive instants were fixed or the impulsive occurrence can be calculated. In fact, it has been known that any computer/machine cannot put impulses in exact time, and there will be errors between the expected time and the actual one. For example, in pest control, we should carry out regular spraying of crops. However, due to man-made reasons or natural causes, in the specified day, we cannot carry out on schedule. But as long as we spray the crops within a few days before or after the expected 
day, this does not affect the growth of crops. Therefore, it is significant to investigate a more practical impulsive scheme concerning the above case.

It is well known that, in the practical application of impulsive control, the impulsive moments at certain instants almost cannot be determined, but an effective impulse interval can be selected; namely, impulse occurs in a time window. For instance, we intend to add an input of impulse at time $t$; our computer/machine may add the impulse in a short time window $(t-\alpha, t+\alpha)$, where $\alpha$ is a small positive number. This time error interval is called impulsive time window which widely exists in our society. Thus, it is essential and urgent to study this class of impulsive system with impulse time window.

Motivated by the above discussion, this paper investigates the exponential stability of Cohen-Grossberg neural networks model with impulsive time window and time-varying discrete delays. The main contributions in this paper can be summarized as follows. First, the impulsive effects we considered can stochastically occur at a definitive time window which is more applicable and more general. Then, the impulsive controllers we considered can be nonlinear and even rely on the states of all the neurons, which remove the restriction that the impulsive functions are linear. Moreover, our theorems do not require the activation functions to be differentiable, bounded, or monotonically nondecreasing. Finally, by utilizing Lyapunov functional theory, inequality technique, and the analysis method, we obtain some novel and effective exponential stability criteria for the Cohen-Grossberg neural networks, and the conditions utilized in this paper are easy to be verified and improve the conditions derived in [14-16].

The rest of this paper is organized as follows. In Section 2, preliminaries and model of Cohen-Grossberg neural networks with time-varying delays are given. Some stability criteria are obtained in Section 3 under the impulsive intermittent controller we assumed. In Section 4, the feasibility and effectiveness of the developed methods are shown by a numerical example. Conclusions are finally reached in Section 5 .

\section{Preliminaries}

In the paper, we consider a type of Cohen-Grossberg neural network model with time-varying delays which is described by

$$
\begin{aligned}
\dot{x}_{i}(t) & =-d_{i}\left(x_{i}(t)\right)\left[c_{i}\left(x_{i}(t)\right)-\sum_{j=1}^{n} a_{i j} f_{j}\left(x_{j}(t)\right)\right. \\
\left.-\sum_{j=1}^{n} b_{i j} g_{j}\left(x_{j}\left(t-\tau_{j}(t)\right)\right)+I_{i}\right], & \\
i \in \mathscr{I} & =\{1,2, \ldots, n\}, t \geq 0,
\end{aligned}
$$

where $x_{i}(t)$ denotes the state of the $i$ th neuron at time $t$, $d_{i}\left(x_{i}(t)\right)$ and $c_{i}\left(x_{i}(t)\right)$ represent the amplification function and behaved function at time $t$, respectively, the time-varying delay $\tau_{j}(t)$ corresponds to the time-varying transmission delay and satisfies $0 \leq \tau_{j}(t) \leq \tau_{j}, f_{j}(\cdot)$ and $g_{j}(\cdot)$ represent the activation functions of the $j$ th neuron, $I_{i}$ corresponds the external input to the $i$ th neuron, and $a_{i j}$ and $b_{i j}$ are constant connection weights and constant delayed connection weights of the $j$ th neuron on the $i$ th neuron, respectively.

The initial condition of system (1) is given by

$$
x_{i}(s)=\phi_{i}(s), \quad s \in[-\tau, 0], i \in \mathscr{I},
$$

where $\tau=\max _{j \in \mathscr{I}}\left\{\tau_{j}\right\}>0, \phi(s)=\left(\phi_{1}(s), \phi_{2}(s), \ldots, \phi_{n}(s)\right)^{T} \epsilon$ $C$, and $C=\left([-\tau, 0], R^{n}\right)$ denotes the Banach space of all continuous functions mapping $[-\tau, 0]$ into $R^{n}$ with norms defined by the following forms:

$$
\begin{aligned}
\|\phi\|_{1} & =\sup _{s \in[-\tau, 0]} \sum_{i=1}^{n}\left|\phi_{i}(s)\right|, \\
\|\phi\|_{\infty} & =\sup _{s \in[-\tau, 0]}\left\{\max _{1 \leq i \leq n}\left|\phi_{i}(s)\right|\right\} .
\end{aligned}
$$

In order to achieve main results, the following assumptions and definition are needed.

$\left(H_{1}\right)$ : For each $i \in \mathscr{I}, d_{i}(\cdot)$ is continuous and there exist positive constants $\underline{d}_{i}$ and $\bar{d}_{i}$ such that

$$
0<\underline{d}_{i} \leq d_{i}(u) \leq \bar{d}_{i}, \quad u \in R .
$$

$\left(H_{2}\right)$ : For each $i \in \mathscr{I}$, function $c_{i}(\cdot): R \rightarrow R$ is continuous and monotonically increasing and there exists real number $c_{i}>0$ such that

$$
\frac{c_{i}(u)-c_{i}(v)}{u-v} \geq c_{i}, \quad \forall u, v \in R, u \neq v .
$$

$\left(H_{3}\right)$ : For each $j \in \mathscr{I}$, functions $f_{j}$ and $g_{j}$ are Lipschitzcontinuous on $R$. That is, there exist positive constants $L_{j}$ and $N_{j}$ such that

$$
\begin{aligned}
& \left|f_{j}(u)-f_{j}(v)\right| \leq L_{j}|u-v|, \\
& \left|g_{j}(u)-g_{j}(v)\right| \leq N_{j}|u-v|,
\end{aligned}
$$

$\forall u, v \in R, u \neq v$.

$\left(H_{4}\right)$ : For each $j \in \mathscr{I}, \tau_{j}(t)$ is differentiable and there exists a constant $\sigma_{j}>0$ such that

$$
\dot{\tau}_{j}(t) \leq \sigma_{j}<1
$$

Definition 1. A constant vector $x^{*}=\left(x_{1}^{*}, x_{2}^{*}, \ldots, x_{n}^{*}\right)^{T}$ is said to be an equilibrium point of system (1) if $x^{*}$ satisfies the following equality:

$$
\begin{aligned}
& 0= d_{i}\left(x_{i}^{*}\right) \\
& \cdot\left[c_{i}\left(x_{i}^{*}\right)-\sum_{j=1}^{n} a_{i j} f_{j}\left(x_{j}^{*}\right)-\sum_{j=1}^{n} b_{i j} g_{j}\left(x_{j}^{*}\right)+I_{i}\right], \\
& i \in \mathscr{I} .
\end{aligned}
$$




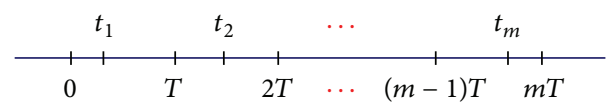

FIGURE 1: The distribution diagram of impulsive occurrences in periodically impulsive control systems with impulse time windows.

For stabilizing the equilibrium point $x^{*}$ of system (1) by means of periodically impulsive control systems with time windows, we mean that in every period $((m-1) T, m T]$ we input an impulse in the time of $t_{m}, m \in Z^{+}=\{1,2, \ldots\}$, where $t_{m}$ is unknown but is within impulse time window $((m-1) T, m T]$. Figure 1 shows distribution diagram of pulsed occurrences. This method is called single impulse control of impulse time window.

Remark 2. It is well known that when someone designs a suitable controller for a dynamical system, impulsive controller is inevitable. However, an accurately impulsive moment chosen is more time-consuming and even is impossible. But it is possible to choose an impulse time window which not only can guarantee the control results but also costs less. In $[17,18]$, the authors considered aperiodically impulse time window, namely, impulse instants $t_{m} \in\left[k_{m} \pm r_{m}\right]$. Yet, in many practical applications, we need periodically impulse time window. For instance, we usually carry out regular spraying of crops in pest control, fish, or prevent HIV virus in a fixed period of time. Therefore, the research problem of periodically impulse time window needs to be solved urgently.

Now, to study the stability behaviors of system (1), the following control system is introduced:

$$
\begin{aligned}
\dot{x}_{i}(t) & =-d_{i}\left(x_{i}(t)\right)\left[c_{i}\left(x_{i}(t)\right)-\sum_{j=1}^{n} a_{i j} f_{j}\left(x_{j}(t)\right)\right. \\
& \left.-\sum_{j=1}^{n} b_{i j} g_{j}\left(x_{j}\left(t-\tau_{j}(t)\right)\right)+I_{i}\right] \\
& +\sum_{m=1}^{\infty} \delta\left(t-t_{m}\right)\left[p_{i m}(x(t))-x_{i}(t)\right], \quad i \in \mathscr{I},
\end{aligned}
$$

where $\delta(t)$ is Dirac delta function, functions $p_{i m}(x)=p_{i m}\left(x_{1}\right.$, $\left.x_{2}, \ldots, x_{n}\right) \in\left[R^{n}, R\right]$ denote the external control inputs which satisfy the following condition.

$\left(H_{5}\right)$ : There exist nonnegative matrices $P_{m}=\left(p_{i j}^{m}\right)_{n \times n}$ such that

$$
\begin{aligned}
& \left|p_{i m}\left(u_{1}, u_{2}, \ldots, u_{n}\right)-p_{i m}\left(v_{1}, v_{2}, \ldots, v_{n}\right)\right| \\
& \quad \leq \sum_{j=1}^{n} p_{i j}^{m}\left|u_{j}-v_{j}\right|
\end{aligned}
$$

hold for any $\left(u_{1}, u_{2}, \ldots, u_{n}\right)^{T} \in R^{n},\left(v_{1}, v_{2}, \ldots, v_{n}\right)^{T} \in R^{n} ; i \in$ $\mathscr{I}$ and $m \in Z^{+}$.

If impulsive functions $p_{i m}(x)=p_{i m}\left(x_{i}\right)$ for all $i \in \mathscr{I}$ and $m \in Z^{+}$, assumption $\left(H_{5}\right)$ is reduced to the following form.
$\left(H_{5}^{\prime}\right)$ : There exist nonnegative diagonal matrices $\bar{P}_{m}=$ $\operatorname{diag}\left(p_{11}^{m}, \ldots, p_{n n}^{m}\right)$ such that

$$
\begin{aligned}
&\left|p_{m}(x)-p_{m}(y)\right| \leq \bar{P}_{m}|x-y|, \\
& \forall x, y \in R^{n}, m \in Z^{+},
\end{aligned}
$$

where $p_{m}(x)=\left(p_{1 m}\left(x_{1}\right), p_{2 m}\left(x_{2}\right), \ldots, p_{n m}\left(x_{n}\right)\right)^{T}$. Such function and assumption have been required in $[19,20]$.

Integrating from $t_{m}-h$ to $t_{m}+h$ both sides of system (9), we have

$$
\begin{gathered}
x_{i}\left(t_{m}+h\right)-x_{i}\left(t_{m}-h\right)=\int_{t_{m}-h}^{t_{m}+h}\left\{-d_{i}\left(x_{i}(t)\right)\right. \\
\cdot\left[c_{i}\left(x_{i}(t)\right)-\sum_{j=1}^{n} a_{i j} f_{j}\left(x_{j}(t)\right)\right. \\
\left.-\sum_{j=1}^{n} b_{i j} g_{j}\left(x_{j}\left(t-\tau_{j}(t)\right)\right)+I_{i}\right] \\
\left.+\sum_{k=1}^{\infty} \delta\left(t-t_{k}\right)\left[p_{i k}(x(t))-x_{i}(t)\right]\right\} d t,
\end{gathered}
$$

where $h>0$ is sufficiently small and $k \in Z^{+}$. As $h \rightarrow 0^{+}$, by applying the properties of the Dirac delta function, we have

$$
x_{i}\left(t_{m}^{+}\right)-x_{i}\left(t_{m}^{-}\right)=p_{i m}\left(x\left(t_{m}\right)\right)-x_{i}\left(t_{m}\right) .
$$

In the paper, we assume that $x(t)=\left(x_{1}(t), x_{2}(t), \ldots\right.$, $\left.x_{n}(t)\right)^{T}$ is left continuous at $t_{m}\left(m \in Z^{+}\right)$; that is, $x_{i}\left(t_{m}\right)=$ $\lim _{t \rightarrow t_{m}^{-}} x_{i}(t)$. In this case, we can get

$$
x_{i}\left(t_{m}^{+}\right)=p_{i m}\left(x\left(t_{m}\right)\right), \quad \text { for } i \in \mathscr{I}, m \in Z^{+} .
$$

Then, from the above equation, system (9) can be rewritten as

$$
\begin{gathered}
\dot{x}_{i}(t)=-d_{i}\left(x_{i}(t)\right)\left[c_{i}\left(x_{i}(t)\right)-\sum_{j=1}^{n} a_{i j} f_{j}\left(x_{j}(t)\right)\right. \\
\left.-\sum_{j=1}^{n} b_{i j} g_{j}\left(x_{j}\left(t-\tau_{j}(t)\right)\right)+I_{i}\right], \quad t \neq t_{m}, \\
x_{i}\left(t_{m}^{+}\right)=p_{i m}\left(x\left(t_{m}\right)\right), \quad i \in \mathscr{I}, m \in Z^{+} .
\end{gathered}
$$

In the sequel, for further study, the following definition is given.

Assume that $R^{n}$ be the space of $n$-dimensional real column vectors. For any $x=\left(x_{1}, x_{2}, \ldots, x_{n}\right)^{T} \in R^{n},\|x\|$ denotes vector norms defined by

$$
\begin{gathered}
\|x\|_{1}=\sum_{i=1}^{n}\left|x_{i}\right|, \\
\|x\|_{\infty}=\max _{i \in \mathscr{I}}\left|x_{i}\right| .
\end{gathered}
$$


Definition 3. The equilibrium point $x^{*}=\left(x_{1}^{*}, x_{2}^{*}, \ldots, x_{n}^{*}\right)^{T}$ of system (1) is said to be globally exponentially stable, if there exist $\lambda>0$ and $M \geq 1$ such that

$$
\left\|x(t)-x^{*}\right\|_{\infty} \leq M\left\|\phi-x^{*}\right\|_{\infty} e^{-\lambda t} \quad \text { for } t \geq 0,
$$

where $x(t)$ is any solution of system (1) with initial condition $\phi \in C$.

In order to stabilize $x^{*}$, the appropriate control functions $p_{i m}(x)$ can be chosen satisfying the following condition.

$\left(H_{5}^{\prime \prime}\right)$ :

$$
p_{i m}\left(x_{1}^{*}, x_{2}^{*}, \ldots, x_{n}^{*}\right)=x_{i}^{*}, \quad i \in \mathscr{I}, m \in Z^{+} .
$$

Remark 4. Obviously, the impulsive control functions $p_{\text {im }}(x)$ satisfying $\left(H_{5}^{\prime \prime}\right)$ always exist in applications. For instance, the following controllers can be chosen:

$$
\begin{aligned}
p_{i m}\left(x\left(t_{m}\right)\right)=x_{i}\left(t_{m}\right)-\gamma_{i m}\left(x_{i}\left(t_{m}\right)-x_{i}^{*}\right), & \\
& \quad i \in \mathscr{F}, m \in Z^{+},
\end{aligned}
$$

where $0<\gamma_{i m}<2$; that is, $\Delta x\left(t_{m}\right)=-\gamma_{i m}\left(x_{i}\left(t_{m}\right)-x_{i}^{*}\right)$, which has been given in $[21,22]$ and satisfies $\left(H_{5}^{\prime \prime}\right)$. In addition, under assumption $\left(H_{5}^{\prime \prime}\right)$, if a constant vector $x^{*}$ is an equilibrium point of system (1), then $x^{*}$ is an equilibrium of system (15).

Transform $x^{*}$ to the origin by using transformation $y_{i}(t)=x_{i}(t)-x_{i}^{*}$ for $i \in \mathscr{I}$. Then system (15) can be rewritten as the following form:

$$
\begin{gathered}
\dot{y}_{i}(t)=-d_{i}\left(y_{i}(t)+x_{i}^{*}\right)\left[\widetilde{c}_{i}\left(y_{i}(t)\right)\right. \\
\left.-\sum_{j=1}^{n} a_{i j} \widetilde{f}_{j}\left(y_{j}(t)\right)-\sum_{j=1}^{n} b_{i j} \tilde{g}_{j}\left(y_{j}\left(t-\tau_{j}(t)\right)\right)\right], \\
y_{i}\left(t_{m}^{+}\right)=\tilde{p}_{i m}\left(y\left(t_{m}\right)\right), \quad i \in \mathcal{F}, m \in t_{m}^{+},
\end{gathered}
$$

where $\widetilde{c}_{i}\left(y_{i}(t)\right)=c_{i}\left(y_{i}(t)+x_{i}^{*}\right)-c_{i}\left(x_{i}^{*}\right), \widetilde{f}_{j}\left(y_{j}(t)\right)=f_{j}\left(y_{j}(t)+\right.$ $\left.x_{j}^{*}\right)-f_{j}\left(x_{j}^{*}\right), \tilde{g}_{j}\left(y_{j}(t)\right)=g_{j}\left(y_{j}(t)+x_{j}^{*}\right)-g_{j}\left(x_{j}^{*}\right)$, and $\widetilde{p}_{\text {im }}\left(y\left(t_{m}\right)\right)=p_{\text {im }}\left(y\left(t_{m}\right)+x^{*}\right)-p_{\text {im }}\left(x^{*}\right)$.

\section{Periodically Impulsive Control Systems with Impulse Time Windows}

In the section, we will consider the globally exponential stability of the equilibrium point $x^{*}$ of neural networks (1) under impulsive intermittent control role. System (20) can be rewritten as follows:

$$
\begin{aligned}
& \dot{y}_{i}(t)=-d_{i}\left(y_{i}(t)+x_{i}^{*}\right)\left[\tilde{c}_{i}\left(y_{i}(t)\right)-\sum_{j=1}^{n} a_{i j} \tilde{f}_{j}\left(y_{j}(t)\right)\right. \\
& \left.-\sum_{j=1}^{n} b_{i j} \tilde{g}_{j}\left(y_{j}\left(t-\tau_{j}(t)\right)\right)\right], \quad t \neq t_{m}, \\
& y_{i}\left(t_{m}^{+}\right)=\widetilde{p}_{i m}\left(y\left(t_{m}\right)\right), \\
& t=t_{m}, t_{m} \in((m-1) T, m T],
\end{aligned}
$$

where $T>0$ denotes the control period; $t_{m}$ is unknown but is determined by a random function within impulse time window $((m-1) T, m T]$.

3.1. Stability Based on 1-Norm. For convenience, we denote

$$
\begin{aligned}
& \lambda_{i}=\underline{d}_{i} c_{i}-\bar{d}_{i} \sum_{j=1}^{n}\left|a_{j i}\right| L_{i}, \\
& \eta_{i}=\bar{d}_{i} \sum_{j=1}^{n}\left|b_{j i}\right| N_{i} .
\end{aligned}
$$

Firstly, we introduce the following condition.

$\left(H_{6}\right): \lambda_{i}-\eta_{i} /\left(1-\sigma_{i}\right)>0$ for any $i \in \mathscr{I}$.

Remark 5. From $\left(H_{6}\right)$, the inequality

$$
\lambda_{i}-\varepsilon^{*}-\frac{\eta_{i}}{1-\sigma_{i}} e^{\varepsilon^{*} \tau_{i}} \geq 0, \quad i \in \mathscr{I}
$$

is satisfied by choosing suitable $\varepsilon^{*}$. The detailed proof is given as follows. Consider the following function:

$$
G_{i}\left(\varepsilon_{i}\right)=\lambda_{i}-\varepsilon_{i}-\frac{\eta_{i}}{1-\sigma_{i}} e^{\varepsilon_{i} \tau_{i}},
$$

where $\varepsilon_{i} \geq 0$ for each $i \in \mathscr{I}$. It is easy to see that

$$
\begin{aligned}
\frac{d G_{i}\left(\varepsilon_{i}\right)}{d \varepsilon_{i}} & =-1-\frac{\eta_{i}}{1-\sigma_{i}} \tau_{i} e^{\varepsilon_{i} \tau_{i}}<0, \\
G_{i}(0) & =\lambda_{i}-\frac{\eta_{i}}{1-\sigma_{i}}>0 .
\end{aligned}
$$

Moreover, $G_{i}\left(\varepsilon_{i}\right)$ is continuous on $[0,+\infty), G_{i}\left(\varepsilon_{i}\right) \rightarrow-\infty$ as $\varepsilon_{i} \rightarrow+\infty$, and there exists positive number $\varepsilon_{i}^{*}$ such that $G_{i}\left(\varepsilon_{i}^{*}\right)=0$ and $G_{i}\left(\varepsilon_{i}\right)>0$ for any $\varepsilon_{i} \in\left(0, \varepsilon_{i}^{*}\right)$. Denoting $\varepsilon^{*}=\min _{i \in \mathcal{F}}\left\{\varepsilon_{i}^{*}\right\}>0$, we have

$$
\lambda_{i}-\varepsilon^{*}-\frac{\eta_{i}}{1-\sigma_{i}} e^{\varepsilon^{*} \tau_{i}} \geq 0, \quad i \in \mathscr{I} .
$$

Theorem 6. Suppose that assumptions $\left(H_{1}\right)-\left(H_{6}\right)$ and $\left(H_{5}^{\prime \prime}\right)$ hold; then the equilibrium point of system (1) is globally exponentially stable under the impulsive intermittent control (14) if the following condition is also satisfied. 
$\left(H_{7}\right):$ There exists a constant $\alpha_{1} \geq 0$ such that

$$
\frac{\ln \rho_{m}}{t_{m}-t_{m-1}} \leq \alpha_{1}<\varepsilon^{*}, \quad m \in Z^{+}
$$

where $\rho_{m}=\max _{i \in \mathcal{F}}\left\{1, \sum_{j=1}^{n}\left(\bar{d}_{i} / \underline{d}_{j}\right) p_{j i}^{m}\right\}, \varepsilon^{*}=\min _{i \in \mathcal{F}}\left\{\varepsilon_{i}^{*}\right\}$, and $\varepsilon_{i}^{*}$ is the unique positive root of equation $\varepsilon_{i}=\lambda_{i}-\left(\eta_{i} /(1-\right.$ $\left.\left.\sigma_{i}\right)\right) e^{\varepsilon_{i} \tau_{i}}$.

Proof. Now we define

$$
\begin{aligned}
& u_{i}(t)=e^{\varepsilon^{*} t} \operatorname{sign}\left(y_{i}(t)\right) \int_{0}^{y_{i}(t)} \frac{1}{d_{i}\left(x_{i}^{*}+s\right)} d s, \\
& u(t)=\sum_{i=1}^{n} u_{i}(t) .
\end{aligned}
$$

From $\left(H_{1}\right)$, it is easy to obtain that

$$
\frac{1}{\bar{d}_{i}} e^{\varepsilon^{*} t}\left|y_{i}(t)\right| \leq u_{i}(t) \leq \frac{1}{\underline{d}_{i}} e^{\varepsilon^{*} t}\left|y_{i}(t)\right|,
$$

for $t \in((m-1) T, m T]$ and $t \neq t_{m}, m \in Z^{+}$; calculating the upper right derivative of $u(t)$ along the solution of system (21), we derived

$$
\begin{aligned}
& D^{+} u(t)=\sum_{i=1}^{n}\left[\varepsilon^{*} u_{i}(t)+e^{\varepsilon^{*} t} \frac{\operatorname{sign}\left(y_{i}(t)\right) \dot{y}_{i}(t)}{d_{i}\left(x_{i}^{*}+y_{i}\right)}\right] \\
& \quad \leq \sum_{i=1}^{n}\left[\varepsilon^{*} u_{i}(t)+e^{\varepsilon^{*} t}\left(-c_{i}\left|y_{i}(t)\right|\right.\right. \\
& +\sum_{j=1}^{n}\left|a_{i j}\right| L_{j}\left|y_{j}(t)\right| \\
& \left.\left.+\sum_{j=1}^{n}\left|b_{i j}\right| N_{j}\left|y_{j}\left(t-\tau_{j}(t)\right)\right|\right)\right] \leq \sum_{i=1}^{n}\left[\varepsilon^{*} u_{i}(t)\right. \\
& +c_{i} \underline{d}_{i} u_{i}(t)+\sum_{j=1}^{n}\left|a_{i j}\right| L_{j} \bar{d}_{j} u_{j}(t) \\
& \left.+\sum_{j=1}^{n} e^{\varepsilon^{*} \tau_{j}}\left|b_{i j}\right| N_{j} \bar{d}_{j} u_{j}\left(t-\tau_{j}(t)\right)\right]=\sum_{i=1}^{n}\left[\left(\varepsilon^{*}-\lambda_{i}\right)\right. \\
& \left.+u_{i}(t)+\eta_{i} e^{\varepsilon^{*} \tau_{i}} u_{i}\left(t-\tau_{i}(t)\right)\right] .
\end{aligned}
$$

Now let us define

$$
V(t)=u(t)+\sum_{i=1}^{n} \eta_{i} e^{\varepsilon^{*} \tau_{i}} \int_{t-\tau_{i}(t)}^{t} \frac{u_{i}(s)}{1-\sigma_{i}} d s,
$$

for $t \geq 0$; calculating the upper right derivative of $V(t)$ along the solution of system (21), we derived

$$
\begin{aligned}
D^{+} V(t) \leq & \sum_{i=1}^{n}\left[\left(\varepsilon^{*}-\lambda_{i}\right) u_{i}(t)+\eta_{i} e^{\varepsilon^{*} \tau_{i}} u_{i}\left(t-\tau_{i}(t)\right)\right] \\
& +\sum_{i=1}^{n} \eta_{i} e^{\varepsilon^{*} \tau_{i}}\left[\frac{u_{i}(t)}{1-\sigma_{i}}-u_{i}\left(t-\tau_{i}(t)\right)\right] \\
= & -\sum_{i=1}^{n}\left(\lambda_{i}-\varepsilon^{*}-\frac{\eta_{i}}{1-\sigma_{i}} e^{\varepsilon^{*} \tau_{i}}\right) u_{i}(t) \leq 0 .
\end{aligned}
$$

So, if $(m-1) T<t \leq t_{m}$, we have

$$
V(t) \leq V\left(((m-1) T)^{+}\right)
$$

if $t_{m}<t \leq m T$, we have

$$
V(t) \leq V\left(t_{m}^{+}\right)
$$

On the other hand, from $(21),\left(H_{5}\right)$, and $\left(H_{7}\right)$, we have

$$
\begin{aligned}
u\left(t_{m}^{+}\right) & \leq e^{\varepsilon^{*} t_{m}} \sum_{i=1}^{n} \frac{1}{\underline{d}_{i}}\left|y_{i}\left(t_{m}^{+}\right)\right| \\
& \leq e^{\varepsilon^{*} t_{m}} \sum_{i=1}^{n} \frac{1}{\underline{d}_{i}} \sum_{j=1}^{n} p_{i j}^{m}\left|y_{j}\left(t_{m}\right)\right| \\
& =e^{\varepsilon^{*} t_{m}} \sum_{i=1}^{n} \sum_{j=1}^{n} \frac{1}{\underline{d}_{j}} p_{j i}^{m}\left|y_{i}\left(t_{m}\right)\right| \\
& \leq \max _{1 \leq i \leq n}\left\{\sum_{j=1}^{n} \frac{\bar{d}_{i}}{\underline{d}_{j}} p_{j i}^{m}\right\} \sum_{i=1}^{n} \frac{1}{\bar{d}_{i}} e^{\varepsilon^{*} t_{m}}\left|y_{i}\left(t_{m}\right)\right| \\
& \leq \rho_{m} u\left(t_{m}\right),
\end{aligned}
$$

for $m \in Z^{+}$; from the definition of $V(t)$, we have

$$
\begin{aligned}
V\left(t_{m}^{+}\right) & =u\left(t_{m}^{+}\right)+\sum_{i=1}^{n} \eta_{i} e^{\varepsilon^{*} \tau_{i}} \int_{t_{m}^{+}-\tau_{i}\left(t_{m}^{+}\right)}^{t_{m}^{+}} \frac{u_{i}(s)}{1-\sigma_{i}} d s \\
& \leq \rho_{m} u\left(t_{m}\right)+\sum_{i=1}^{n} \eta_{i} e^{\varepsilon^{*} \tau_{i}} \int_{t_{m}-\tau_{i}\left(t_{m}\right)}^{t_{m}} \frac{u_{i}(s)}{1-\sigma_{i}} d s \\
& \leq \rho_{m} V\left(t_{m}\right) .
\end{aligned}
$$

From (33) and (34), we obtain the following cases. If $0<t \leq t_{1}$, then we have that

$$
V(t) \leq V\left(0^{+}\right) \leq \rho_{0} V(0),
$$

where $\rho_{0}=1$. If $t_{1}<t \leq T$, we have that

$$
V(t) \leq V\left(t_{1}^{+}\right) \leq \rho_{1} V\left(t_{1}\right) \leq \rho_{1} \rho_{0} V(0) .
$$

If $T<t \leq t_{2}$, then we have that

$$
V(t) \leq V\left(T^{+}\right) \leq \rho_{1} \rho_{0} V(0) .
$$


If $t_{2}<t \leq 2 T$, we have that

$$
V(t) \leq V\left(t_{2}^{+}\right) \leq \rho_{2} V\left(t_{2}\right) \leq \rho_{2} \rho_{1} \rho_{0} V(0)
$$

Below we will use induction method to prove that the following statements are true.

For $(m-1) T<t \leq t_{m}$,

$$
V(t) \leq V\left(((m-1) T)^{+}\right) \leq \rho_{m-1} \cdots \rho_{1} \rho_{0} V(0),
$$

and, for $t_{m}<t \leq m T$,

$$
V(t) \leq V\left(t_{m}^{+}\right) \leq \rho_{m} \rho_{m-1} \cdots \rho_{1} \rho_{0} V(0) .
$$

As for $m=1$, from the above analysis, we know that inequalities (41) and (42) hold.

Assume that inequalities (41) and (42) are true for all $m=$ $1,2, \ldots, k$; then, for any integer $m$ satisfying $(m-1) T<t \leq t_{m}$,

$$
V(t) \leq \rho_{m-1} \cdots \rho_{1} \rho_{0} V(0), \quad m=1,2, \ldots, k,
$$

and, for $t_{m}<t \leq m T$,

$$
V(t) \leq \rho_{m} \rho_{m-1} \cdots \rho_{1} \rho_{0} V(0), \quad m=1,2, \ldots, k .
$$

When $m=k+1$, if $k T<t \leq t_{k+1}$, then

$$
V(t) \leq V\left((k T)^{+}\right) \leq \rho_{k} \rho_{k-1} \cdots \rho_{1} \rho_{0} V(0) .
$$

For $t_{k+1}<t \leq(k+1) T$,

$$
\begin{aligned}
V(t) & \leq V\left(t_{k+1}^{+}\right) \leq \rho_{k+1} V\left(t_{k+1}\right) \\
& \leq \rho_{k+1} \rho_{k} \cdots \rho_{1} \rho_{0} V(0) .
\end{aligned}
$$

Then, by the induction, we see that (41) and (42) hold.

In view of $\left(\mathrm{H}_{7}\right)$, we obtain

$$
\rho_{m} \leq e^{\alpha_{1}\left(t_{m}-t_{m-1}\right)}, \quad m \in Z^{+} .
$$

So, for $(m-1) T<t \leq t_{m}$, we can get

$$
\begin{aligned}
u(t) & \leq V(t) \leq \rho_{m-1} \cdots \rho_{1} \rho_{0} V(0) \\
& \leq e^{\alpha_{1}\left(t_{m-1}-t_{m-2}+\cdots+t_{1}-t_{0}\right)} V(0)=e^{\alpha_{1} t_{m-1}} V(0) \\
& <e^{\alpha_{1} t} V(0),
\end{aligned}
$$

and, for $t_{m}<t \leq m T$, we can get

$$
\begin{aligned}
u(t) & \leq V(t) \leq \rho_{m} \cdots \rho_{1} \rho_{0} V(0) \\
& \leq e^{\alpha_{1}\left(t_{m}-t_{m-1}+\cdots+t_{1}-t_{0}\right)} V(0)=e^{\alpha_{1} t_{m}} V(0) \\
& <e^{\alpha_{1} t} V(0) .
\end{aligned}
$$

Therefore, for any $t \geq 0$, we always have

$$
u(t) \leq V(t)<e^{\alpha_{1} t} V(0) .
$$

It follows that

$$
\begin{aligned}
& \sum_{i=1}^{n}\left|y_{i}(t)\right|<\max _{i \in \mathscr{I}}\left\{\bar{d}_{i}\right\} e^{-\left(\varepsilon^{*}-\alpha_{1}\right) t} V(0) \\
& \leq \max _{i \in \mathscr{I}}\left\{\bar{d}_{i}\right\} e^{-\left(\varepsilon^{*}-\alpha_{1}\right) t} \\
& \cdot\left[u(0)+\sum_{i=1}^{n} \eta_{i} e^{\varepsilon^{*} \tau_{i}} \int_{-\tau(0)}^{0} \frac{u_{i}(s)}{1-\sigma_{i}} d s\right] \\
& \quad \leq \max _{i \in \mathscr{I}}\left\{\bar{d}_{i}\right\} e^{-\left(\varepsilon^{*}-\alpha_{1}\right) t}\left[1+\max _{i \in \mathscr{I}}\left\{\frac{\tau \eta_{i} e^{\varepsilon^{*} \tau_{i}}}{1-\sigma_{i}}\right\}\right] \\
& \cdot \sup _{-\tau \leq s \leq 0} \sum_{i=1}^{n} u_{i}(s) \leq \frac{\max _{i \in \mathscr{I}}\left\{\bar{d}_{i}\right\}}{\min _{i \in \mathscr{I}}\left\{\underline{d}_{i}\right\}} \\
& \cdot e^{-\left(\varepsilon^{*}-\alpha_{1}\right) t}\left[1+\max _{i \in \mathscr{I}}\left\{\frac{\tau \eta_{i} e^{\varepsilon^{*} \tau_{i}}}{1-\sigma_{i}}\right\}\right] \sup _{-\tau \leq s \leq 0} \sum_{i=1}^{n}\left|y_{i}(s)\right| \\
& \leq M e^{-\left(\varepsilon^{*}-\alpha_{1}\right) t} \sup _{-\tau \leq s \leq 0} \sum_{i=1}^{n}\left|y_{i}(s)\right|,
\end{aligned}
$$

where

$$
M=\frac{\max _{i \in \mathscr{F}}\left\{\bar{d}_{i}\right\}}{\min _{i \in \mathscr{I}}\left\{\underline{d}_{i}\right\}}\left[1+\max _{i \in \mathscr{I}}\left\{\frac{\tau \eta_{i} e^{\varepsilon^{*} \tau_{i}}}{1-\sigma_{i}}\right\}\right] \geq 1,
$$

which means that

$$
\left\|x(t)-x^{*}\right\|_{1} \leq M\left\|\phi-x^{*}\right\|_{1} e^{-\left(\varepsilon^{*}-\alpha_{1}\right) t} .
$$

Therefore, the proof of Theorem 6 is completed.

3.2. Stability Based on $\infty$-Norm. For convenience, we denote

$$
\begin{aligned}
& \tilde{\lambda}_{i}=c_{i}-\sum_{j=1}^{n}\left|a_{i j}\right| L_{j}, \\
& \widetilde{\eta}_{i}=\sum_{j=1}^{n}\left|b_{i j}\right| N_{j} .
\end{aligned}
$$

Firstly, we introduce the below condition.

$\left(H_{6}^{\prime}\right): \widetilde{\lambda}_{i}-\widetilde{\eta}_{i}>0$ for any $i \in \mathscr{I}$.

Remark 7. From $\left(H_{6}^{\prime}\right)$, the inequality

$$
\tilde{\lambda}_{i}-\frac{\varepsilon^{* *}}{\underline{d}_{i}}-\tilde{\eta}_{i}>0, \quad i \in \mathscr{I}
$$

is satisfied by choosing appropriate $\varepsilon^{* *}$. The detailed proof is presented as follows. Consider the following function:

$$
G_{i}\left(\varepsilon_{i}\right)=\tilde{\lambda}_{i}-\frac{\varepsilon_{i}}{\underline{d}_{i}}-\tilde{\eta}_{i} e^{\varepsilon_{i} \tau}
$$

where $\varepsilon_{i} \geq 0$ for each $i \in \mathscr{I}$. Similar to Remark 7, we can easily obtain that there exists positive number $\varepsilon_{i}^{* *}$ such that 
$G_{i}\left(\varepsilon_{i}^{* *}\right)=0$ and $G_{i}\left(\varepsilon_{i}\right)>0$ for any $\varepsilon_{i} \in\left(0, \varepsilon_{i}^{* *}\right)$. Denoting $\varepsilon^{* *}=\min _{i \in \mathscr{I}}\left\{\varepsilon_{i}^{* *}\right\}>0$, we have

$$
\tilde{\lambda}_{i}-\frac{\varepsilon^{* *}}{\underline{d}_{i}}-\tilde{\eta}_{i} e^{\varepsilon^{* *} \tau} \geq 0, \quad i \in \mathcal{I},
$$

which implies that

$$
\tilde{\lambda}_{i}-\frac{\varepsilon^{* *}}{\underline{d}_{i}}-\tilde{\eta}_{i}>0, \quad i \in \mathscr{I} .
$$

Theorem 8. Suppose that assumptions $\left(H_{1}\right)-\left(H_{3}\right),\left(H_{5}\right)$, $\left(H_{5}^{\prime \prime}\right)$, and $\left(H_{6}^{\prime}\right)$ hold; then the equilibrium point of system (1) is globally exponentially stable under the impulsive intermittent control (14) if the following condition is also satisfied.

$\left(H_{7}^{\prime}\right)$ : There exists a constant $\alpha_{2} \geq 0$ such that

$$
\frac{\ln \rho_{m}}{t_{m}-t_{m-1}} \leq \alpha_{2}<\varepsilon^{* *}, \quad m \in Z^{+},
$$

where $\rho_{m}=\max _{i \in \mathscr{F}}\left\{1, \sum_{j=1}^{n} p_{i j}^{m}\right\}, \varepsilon^{* *}=\min _{i \in \mathcal{I}^{\prime}}\left\{\varepsilon_{i}^{* *}\right\}$, and $\varepsilon_{i}^{* *}$ is the unique positive root of equation $\varepsilon_{i} / \underline{d}_{i}=\widetilde{\lambda}_{i}-\widetilde{\eta}_{i} e^{\varepsilon_{i} \tau}$.

Proof. From $\left(H_{1}\right)-\left(H_{3}\right)$ and (21), for $t \neq t_{m}$, we have

$$
\begin{aligned}
& D^{+}\left|y_{i}(t)\right| \leq d_{i}\left(y_{i}(t)+x_{i}^{*}\right)\left[-c_{i}\left|y_{i}(t)\right|\right. \\
& \left.\quad+\sum_{j=1}^{n}\left|a_{i j}\right| L_{j}\left|y_{j}(t)\right|+\sum_{j=1}^{n}\left|b_{i j}\right| N_{j}\left|y_{j}\left(t-\tau_{j}(t)\right)\right|\right] .
\end{aligned}
$$

Denote

$$
\begin{aligned}
M & =\sup _{-\tau \leq s \leq 0}\left\{\max _{i \in \mathscr{I}}\left|y_{i}(s)\right|\right\}, \\
S(t) & =M e^{-\varepsilon^{* *} t},
\end{aligned}
$$

where $t \geq-\tau$ and $i \in \mathscr{I}$. It is easy to see that

$$
\begin{aligned}
\left|y_{i}(t)\right| \leq M=S(t) e^{\varepsilon^{* *} t} \leq S(t)< & h S(t), \\
& \forall t \in[-\tau, 0], i \in \mathscr{I},
\end{aligned}
$$

where $h>1$ is a constant.

In the following, we will prove that

$$
\left|y_{i}(t)\right|<h S(t) \quad \forall t \in\left(0, t_{1}\right], i \in \mathscr{I} .
$$

Otherwise, there exist $l_{1} \in \mathscr{I}$ and $p_{1} \in\left(0, t_{1}\right]$ such that

$$
\left|y_{l_{1}}\left(p_{1}\right)\right|=h S\left(p_{1}\right) \text {, }
$$

and, for any $i \in \mathscr{I}$,

$$
\begin{aligned}
\left|y_{i}\left(p_{1}\right)\right| & \leq h S\left(p_{1}\right), \\
\left|y_{i}(t)\right| & <h S(t) \quad \text { for } t \in\left(0, p_{1}\right) .
\end{aligned}
$$

From (62) and (65), for any $i \in \mathscr{I}$,

$$
\left|y_{i}(t)\right|<h S(t) \quad \forall t \in\left[-\tau, p_{1}\right) .
$$

If $\tau_{j}\left(p_{1}\right)=0$ for any $j \in \mathscr{I}$, then, using (55) and (60), we obtain

$$
\begin{aligned}
& D^{+}\left(\left|y_{l_{1}}\left(p_{1}\right)\right|-h S\left(p_{1}\right)\right) \leq d_{l_{1}}\left(y_{l_{1}}\left(p_{1}\right)+x_{l_{1}}^{*}\right) \\
& \quad \cdot\left[-c_{l_{1}}\left|y_{l_{1}}\left(p_{1}\right)\right|+\sum_{j=1}^{n}\left|a_{i j}\right| L_{j}\left|y_{j}\left(p_{1}\right)\right|\right. \\
& \left.\quad+\sum_{j=1}^{n}\left|b_{i j}\right| N_{j}\left|y_{j}\left(p_{1}\right)\right|\right]+\varepsilon^{* *} h S\left(p_{1}\right) \\
& \quad \leq d_{l_{1}}\left(y_{l_{1}}\left(p_{1}\right)+x_{l_{1}}^{*}\right)\left(-\tilde{\lambda}_{l_{1}}+\widetilde{\eta}_{l_{1}}+\frac{\varepsilon^{* *}}{\underline{d}_{l_{1}}}\right) h S\left(p_{1}\right) \\
& \quad<0 .
\end{aligned}
$$

If there exist some $r \in \mathscr{I}$ such that $\tau_{r}\left(p_{1}\right)>0$, then, from (66), we have

$$
\left|y_{r}\left(p_{1}-\tau_{r}\left(p_{1}\right)\right)\right|<h S\left(p_{1}-\tau_{r}\left(p_{1}\right)\right) .
$$

From this together with (65), we have

$$
D^{+}\left(\left|y_{l_{1}}\left(p_{1}\right)\right|-h S\left(p_{1}\right)\right) \leq d_{l_{1}}\left(y_{l_{1}}\left(p_{1}\right)+x_{l_{1}}^{*}\right)
$$

$$
\begin{aligned}
& \cdot\left[-c_{l_{1}}\left|y_{l_{1}}\left(p_{1}\right)\right|+\sum_{j=1}^{n}\left|a_{i j}\right| L_{j}\left|y_{j}\left(p_{1}\right)\right|\right. \\
& \left.+\sum_{j=1}^{n}\left|b_{i j}\right| N_{j}\left|y_{j}\left(p_{1}-\tau_{j}\left(p_{1}\right)\right)\right|\right]+\varepsilon^{* *} h S\left(p_{1}\right) \\
& <d_{l_{1}}\left(y_{l_{1}}\left(p_{1}\right)+x_{l_{1}}^{*}\right)\left[-c_{l_{1}}\left|y_{l_{1}}\left(p_{1}\right)\right|\right.
\end{aligned}
$$$$
+\sum_{j=1}^{n}\left|a_{i j}\right| L_{j}\left|y_{j}\left(p_{1}\right)\right|
$$

$$
\begin{aligned}
& \left.+\sum_{j=1}^{n}\left|b_{i j}\right| N_{j} h S\left(p_{1}-\tau_{j}\left(p_{1}\right)\right)\right]+\varepsilon^{* *} h S\left(p_{1}\right) \\
& \leq d_{l_{1}}\left(y_{l_{1}}\left(p_{1}\right)+x_{l_{1}}^{*}\right)\left(-\tilde{\lambda}_{l_{1}}+\widetilde{\eta}_{l_{1}} e^{\varepsilon^{* *} \tau}+\frac{\varepsilon^{* *}}{\underline{d}_{l_{1}}}\right) \\
& \cdot h S\left(p_{1}\right)<0 .
\end{aligned}
$$

From what has been discussed above, we obtain

$$
D^{+}\left(\left|y_{l_{1}}\left(p_{1}\right)\right|-h S\left(p_{1}\right)\right)<0 .
$$

Then there exists $\theta_{1}>0$ such that

$$
D^{+}\left(\left|y_{l_{1}}(t)\right|-h S(t)\right)<0, \quad \text { for } t \in\left(p_{1}-\theta_{1}, p_{1}\right) \text {. }
$$


Integrating above inequality from $t$ to $p_{1}$, we have

$$
\left|y_{l_{1}}(t)\right|>h S(t), \quad \text { for } t \in\left(p_{1}-\theta_{1}, p_{1}\right),
$$

which leads to a contradiction with (65); then inequality (63) holds.

Moreover, from $\left(\mathrm{H}_{5}\right)$ and the definition of $\rho_{1}$, we have

$$
\left|y_{i}\left(t_{1}^{+}\right)\right| \leq \sum_{j=1}^{n} p_{i j}^{1}\left|y_{j}\left(t_{1}\right)\right|<\sum_{j=1}^{n} p_{i j}^{1} h S\left(t_{1}\right) \leq \rho_{1} h S\left(t_{1}\right) .
$$

Now, we prove that, for $t \in\left(t_{1}, T\right]$ and $i \in \mathscr{I}$,

$$
\left|y_{i}(t)\right|<\rho_{1} h S(t) \text {. }
$$

Otherwise, there exist $l_{2} \in \mathscr{I}$ and $p_{2} \in\left(t_{1}, T\right]$ such that

$$
\left|y_{l_{2}}\left(p_{2}\right)\right|=\rho_{1} h S\left(p_{2}\right)
$$

and, for any $i \in \mathscr{I}$,

$$
\begin{aligned}
\left|y_{i}\left(p_{2}\right)\right| & \leq \rho_{1} h S\left(p_{2}\right), \\
\left|y_{i}(t)\right| & <\rho_{1} h S(t) \quad \text { for } t \in\left(t_{1}, p_{2}\right) .
\end{aligned}
$$

For $j \in \mathscr{I}$, if $t_{1}<p_{2}-\tau_{j}\left(p_{2}\right)<p_{2}$, it follows from (76) that

$$
\left|y_{j}\left(p_{2}-\tau_{j}\left(p_{2}\right)\right)\right|<\rho_{1} h S\left(p_{2}-\tau_{j}\left(p_{2}\right)\right),
$$

and if $-\tau<p_{2}-\tau_{j}\left(p_{2}\right) \leq t_{1}$, from (62) and (63), we have

$$
\begin{aligned}
\left|y_{j}\left(p_{2}-\tau_{j}\left(p_{2}\right)\right)\right| & <h S\left(p_{2}-\tau_{j}\left(p_{2}\right)\right) \\
& \leq \rho_{1} h S\left(p_{2}-\tau_{j}\left(p_{2}\right)\right) .
\end{aligned}
$$

Hence, for any $j \in \mathscr{I}$, we always have

$$
\left|y_{j}\left(p_{2}-\tau_{j}\left(p_{2}\right)\right)\right|<\rho_{1} h S\left(p_{2}-\tau_{j}\left(p_{2}\right)\right) .
$$

Then

$$
\begin{aligned}
D^{+} & \left(\left|y_{l_{2}}\left(p_{2}\right)\right|-\rho_{1} h S\left(p_{2}\right)\right) \leq d_{l_{2}}\left(y_{l_{2}}\left(p_{2}\right)+x_{l_{2}}^{*}\right) \\
& \cdot\left[-c_{l_{2}}\left|y_{l_{2}}\left(p_{2}\right)\right|+\sum_{j=1}^{n}\left|a_{i j}\right| L_{j}\left|y_{j}\left(p_{2}\right)\right|\right. \\
& \left.+\sum_{j=1}^{n}\left|b_{i j}\right| N_{j}\left|y_{j}\left(p_{2}-\tau_{j}\left(p_{2}\right)\right)\right|\right]+\rho_{1} \varepsilon^{* *} h S\left(p_{2}\right) \\
& <d_{l_{1}}\left(y_{l_{1}}\left(p_{1}\right)+x_{l_{1}}^{*}\right)\left[-c_{l_{2}}\left|y_{l_{2}}\left(p_{2}\right)\right|\right. \\
+ & \sum_{j=1}^{n}\left|a_{i j}\right| L_{j}\left|y_{j}\left(p_{2}\right)\right| \\
+ & \left.\sum_{j=1}^{n}\left|b_{i j}\right| N_{j} \rho_{1} h S\left(p_{2}-\tau_{j}\left(p_{2}\right)\right)\right]+\varepsilon^{* *} \rho_{1} h S\left(p_{2}\right) \\
\leq & \left(-\tilde{\lambda}_{l_{2}}+\widetilde{\eta}_{l_{2}} e^{\varepsilon^{* *} \tau}+\frac{\varepsilon^{* *}}{\underline{d}_{l_{2}}}\right) \rho_{1} h S\left(p_{2}\right)<0 .
\end{aligned}
$$

From what has been discussed above, we obtain

$$
D^{+}\left(\left|y_{l_{2}}\left(p_{2}\right)\right|-\rho_{1} h S\left(p_{2}\right)\right)<0
$$

Then there exists $\theta_{2}>0$ such that

$$
D^{+}\left(\left|y_{l_{2}}(t)\right|-\rho_{1} h S(t)\right)<0, \quad \text { for } t \in\left(p_{2}-\theta_{2}, p_{2}\right) .
$$

Integrating above inequality from $t$ to $p_{2}$, we have

$$
\left|y_{l_{2}}(t)\right|>\rho_{1} h S(t), \quad \text { for } t \in\left(p_{2}-\theta_{2}, p_{2}\right),
$$

which leads to a contradiction with (76); then inequality (74) holds.

Below we will use induction method to prove that the following statements are true.

For $(m-1) T<t \leq t_{m}$

$$
\left|y_{i}(t)\right|<\rho_{0} \rho_{1} \cdots \rho_{m-1} h S(t),
$$

and, for $t_{m}<t \leq m T$,

$$
\left|y_{i}(t)\right|<\rho_{0} \rho_{1} \cdots \rho_{m} h S(t),
$$

where $\rho_{0}=1$.

As for $m=1$, from (63) and (74), we know that inequalities (84) and (85) hold.

Assume that inequalities (84) and (85) are true for all $m=$ $1,2, \ldots, k$; then, for any integer $m$ satisfying $(m-1) T<t \leq t_{m}$,

$$
\left|y_{i}(t)\right|<\rho_{0} \rho_{1} \cdots \rho_{m-1} h S(t), \quad m=1,2, \ldots, k,
$$

and, for $t_{m}<t \leq m T$,

$$
\left|y_{i}(t)\right|<\rho_{0} \rho_{1} \cdots \rho_{m} h S(t), \quad m=1,2, \ldots, k .
$$

For $m=k+1$, it follows that

$$
\begin{aligned}
\left|y_{i}\left(t_{k+1}^{+}\right)\right| & \leq \sum_{j=1}^{n} p_{i j}^{k+1}\left|y_{j}\left(t_{k+1}\right)\right| \\
& <\rho_{0} \rho_{1} \rho_{2} \cdots \rho_{k} \rho_{k+1} h S\left(t_{k+1}\right) .
\end{aligned}
$$

Similar to the proof of (63), we can prove that

$$
\left|y_{i}(t)\right|<\rho_{0} \rho_{1} \cdots \rho_{k} h S(t)
$$

holds for $k T<t \leq t_{k+1}$. And, similar to (74), we can verify that

$$
\left|y_{i}(t)\right|<\rho_{0} \rho_{1} \cdots \rho_{k} \rho_{k+1} h S(t)
$$

holds for $t_{k+1}<t \leq(k+1) T$. Here, for simplicity, the process of those proofs is omitted. Then, by the induction, we see that (84) and (85) hold.

Let $h \rightarrow 1$; we have

$$
\begin{aligned}
& \left|y_{i}(t)\right| \leq \rho_{0} \rho_{1} \cdots \rho_{m-1} S(t) \\
& \qquad \text { for }(m-1) T<t \leq t_{m}, m \in Z^{+}, \\
& \left|y_{i}(t)\right| \leq \rho_{0} \rho_{1} \cdots \rho_{m-1} \rho_{m} S(t)
\end{aligned}
$$


In view of $\left(H_{7}^{\prime}\right)$, we obtain

$$
\rho_{m} \leq e^{\alpha_{2}\left(t_{m}-t_{m-1}\right)}, \quad m \in Z^{+} .
$$

So, for $(m-1) T<t \leq t_{m}$, we derive

$$
\begin{aligned}
\left|y_{i}(t)\right| & \leq M e^{\alpha_{2}\left(t_{1}-t_{0}\right)} e^{\alpha_{1}\left(t_{2}-t_{1}\right)} \cdots e^{\alpha_{2}\left(t_{m-1}-t_{m-2}\right)} e^{-\varepsilon^{* *} t} \\
& =M e^{-\left(\varepsilon^{* *} t-\alpha_{2} t_{m-1}\right)}<M e^{-\left(\varepsilon^{* *}-\alpha_{2}\right) t}
\end{aligned}
$$

and, for $t_{m}<t \leq m T$, we obtain

$$
\begin{aligned}
\left|y_{i}(t)\right| & \leq M e^{\alpha_{2}\left(t_{1}-t_{0}\right)} e^{\alpha_{2}\left(t_{2}-t_{1}\right)} \cdots e^{\alpha_{2}\left(t_{m}-t_{m-1}\right)} e^{-\varepsilon^{*} t} \\
& =M e^{-\left(\varepsilon^{* *} t-\alpha_{2} t_{m}\right)}<M e^{-\left(\varepsilon^{* *}-\alpha_{2}\right) t} .
\end{aligned}
$$

Therefore, for any $t \geq 0$, we always have

$$
\left|y_{i}(t)\right|<M e^{-\left(\varepsilon^{* *}-\alpha_{2}\right) t},
$$

which implies that

$$
\begin{aligned}
\left\|x(t)-x^{*}\right\|_{\infty} & \leq \sup _{-\tau \leq s \leq 0}\left\{\max _{j \in \mathscr{I}}\left|y_{j}(s)\right|\right\} e^{-\left(\varepsilon^{* *}-\alpha_{2}\right) t} \\
& =\left\|\phi-x^{*}\right\|_{\infty} e^{-\left(\varepsilon^{* *}-\alpha_{2}\right) t},
\end{aligned}
$$

for $t \geq 0$. The proof of Theorem 8 is completed.

Remark 9. If impulsive controllers (14) reduce to (19), it is obvious that conditions $\left(H_{5}\right)$ and $\left(H_{5}^{\prime \prime}\right)$ are satisfied and $P_{m}=$ $E$ for $i \in \mathscr{I}$ and $m \in Z^{+}$, where $E$ denotes the identity matrix. Moreover, it is easy to see that $\rho_{m}=1$ for $m \in Z^{+}$in Theorems 6 and 8 .

Corollary 10. Suppose that assumptions $\left(H_{1}\right)-\left(H_{6}\right)$ and $\left(H_{5}^{\prime \prime}\right)$ hold; then the equilibrium point of system (1) is exponentially stable under the impulsive intermittent control (14) if the following condition is also satisfied.

$\left(\mathrm{H}_{7}\right)$ :

$$
\rho_{m}=\max _{i \in \mathscr{I}}\left\{1, \sum_{j=1}^{n} \frac{\bar{d}_{i}}{\underline{d}_{j}} p_{j i}^{m}\right\}=1, \quad m \in Z^{+} .
$$

Corollary 11. Suppose that assumptions $\left(H_{1}\right)-\left(H_{3}\right),\left(H_{5}\right)$, $\left(H_{5}^{\prime \prime}\right)$, and $\left(H_{6}^{\prime}\right)$ hold; then the equilibrium point of system (1) is exponentially stable under the impulsive intermittent control (14) if the following condition is also satisfied.

$\left(H_{7}^{\prime}\right)$ :

$$
\rho_{m}=\max _{i \in \mathscr{I}}\left\{1, \sum_{j=1}^{n} p_{i j}^{m}\right\}=1, \quad m \in Z^{+}
$$

Remark 12. In the paper, Theorems 6 and 8 are proven based on 1-norm and $\infty$-norm to ensure the global exponential stability of the equilibrium. Compared with Theorem 6 , the condition for time-varying delays, $\dot{\tau}_{j}(t) \leq \sigma_{j}<1$, is removed in Theorem 8.
Remark 13. When $d_{i}(\cdot)=1$, the Cohen-Grossberg neural networks in the paper turn out to the models considered in $[12,14-16,19,21-23]$. Therefore, from this point, we can get the conclusion that the model in this paper is general. In [14$16,24,25]$, the authors considered delayed Cohen-Grossberg neural networks by using fixed point impulsive theorem. In fact, we know that there will be errors between the expected time and the actual one. In many applications, it may be impossible to determine the impulsive sequences. After introducing the time window, impulse interval is described by parameters of the time window. Moreover, in [14-16], the authors require the following condition:

$$
\min _{1 \leq i \leq 2}\left(c_{i}-\sum_{j=1}^{2}\left|a_{j i}\right| L_{i}\right)>\max _{1 \leq i \leq 2}\left(\sum_{j=1}^{2}\left|b_{j i}\right| L_{i}\right) .
$$

Obviously, this condition is very strong. However, in our paper, we only need the following condition:

$$
c_{i}-\sum_{j=1}^{2}\left|a_{j i}\right| L_{i}>\sum_{j=1}^{2}\left|b_{j i}\right| L_{i}
$$

So, our results are less weak than results of [14-16].

Remark 14. From Theorems 6 and 8, we have

$$
\begin{aligned}
& 2 T \geq \frac{1}{\varepsilon^{*}} \ln \left(\max _{i \in \mathscr{I}}\left\{1, \sum_{j=1}^{n} \frac{\bar{d}_{i}}{\underline{d}_{j}} p_{j i}^{m}\right\}\right), \\
& 2 T \geq \frac{1}{\varepsilon^{* *}} \ln \left(\max _{i \in \mathscr{I}}\left\{1, \sum_{j=1}^{n} p_{i j}^{m}\right\}\right),
\end{aligned}
$$

respectively. One can easily observe that the left hand of the above inequality is formed by the parameters of time window, and the right hand expresses requirement of the minimum time interval of impulse. Hence, the above inequality describes the relationship between the parameter of impulse time window of the system and the exponential rate.

\section{Numerical Simulations}

In the section, we present an example to show the effectiveness of the results obtained in this paper.

Example. Consider the following Cohen-Grossberg neural networks model with time-varying variable delays:

$$
\begin{gathered}
\dot{x}_{i}(t)=-d_{i}\left(x_{i}(t)\right)\left[c_{i}\left(x_{i}(t)\right)-\sum_{j=1}^{2} a_{i j} f_{j}\left(x_{j}(t)\right)\right. \\
\left.-\sum_{j=1}^{2} b_{i j} g_{j}\left(x_{j}\left(t-\tau_{j}(t)\right)\right)+I_{i}\right], \quad i=1,2,
\end{gathered}
$$

where $a_{11}=0.5, a_{12}=0.15, a_{21}=0.6, a_{22}=-0.5, b_{11}=0.85$, $b_{12}=-0.5, b_{21}=0.2, b_{22}=0.5, d_{1}\left(x_{1}\right)=1+1 /\left(5+x_{1}^{2}\right)$, 
$d_{2}\left(x_{2}\right)=2-1 /\left(5+x_{2}^{2}\right), c_{1}\left(x_{1}\right)=2.5 x_{1}, c_{2}\left(x_{2}\right)=2.2 x_{2}, \tau_{1}(t)=$ $1-0.2|\sin t|, \tau_{2}(t)=0.9-0.1|\cos t|$, and take the activation function as $f_{j}(x)=g_{j}(x)=(1 / 2)(|x+1|-|x-1|), I_{1}=0$, and $I_{2}=0$.

In the following, we introduce the following impulsive controllers:

$$
\begin{array}{ll}
x_{1}\left(t_{m}^{+}\right)=-0.48 \sin \left(x_{1}\left(t_{m}\right)\right)-0.4 x_{2}\left(t_{m}\right), & \\
& m \in Z^{+}, \\
x_{2}\left(t_{m}^{+}\right)=0.52 x_{1}\left(t_{m}\right)+0.42 \sin \left(x_{2}\left(t_{m}\right)\right), & \\
& m \in Z^{+} .
\end{array}
$$

We can verify that $(0,0)^{T}$ is an equilibrium of system (103). Let $T=1$; about the jumps, we suppose that

$$
\begin{gathered}
t_{1}=0.5, \\
t_{2}=1.5, \\
t_{3}=2.5, \\
\vdots
\end{gathered}
$$

So that, in interval $[0,1]$, we have only one jump.

By simple computing, we get $c_{1}=2.5, c_{2}=2.2, \bar{d}_{1}=1.2$, $\underline{d}_{1}=1, \bar{d}_{2}=2, \underline{d}_{2}=1.8, \tau=1, L_{1}=L_{2}=N_{1}=N_{2}=1$, $\tilde{\lambda}_{1}=1.85, \tilde{\lambda}_{2}=1.1, \tilde{\eta}_{1}=1.35, \tilde{\eta}_{2}=0.7$, and

$$
\begin{aligned}
& P_{m}=\left(\begin{array}{ll}
0.48 & 0.4 \\
0.52 & 0.42
\end{array}\right), \\
& \rho_{m}=\max _{i \in \mathscr{I}}\left\{1, \sum_{j=1}^{n} p_{i j}^{m}\right\}=1 ;
\end{aligned}
$$

then the conditions of Theorem 8 are satisfied. It follows from Theorem 8 that system (103) is exponentially stable. The face can be seen by the numerical simulation in Figures 2, 3, and 4.

\section{Conclusion}

In this paper, the global exponential stability of CohenGrossberg neural networks model with time-varying delays has been studied. Particularly, several new sufficient conditions ensuring the exponential stability of Cohen-Grossberg neural networks are obtained via periodically impulsive intermittent control. Evidently, compared with correspondingly previous works $[14,15]$, our results are less conservative and more general. In addition, in our paper, the activation functions are not differentiable, bounded, or monotonically nondecreasing, and the impulsive controllers, which remove the condition that the impulsive functions are linear, can be nonlinear and even rely on the states of all the neurons. Finally, some numerical simulations are given to illustrate the effectiveness of the proposed theories.

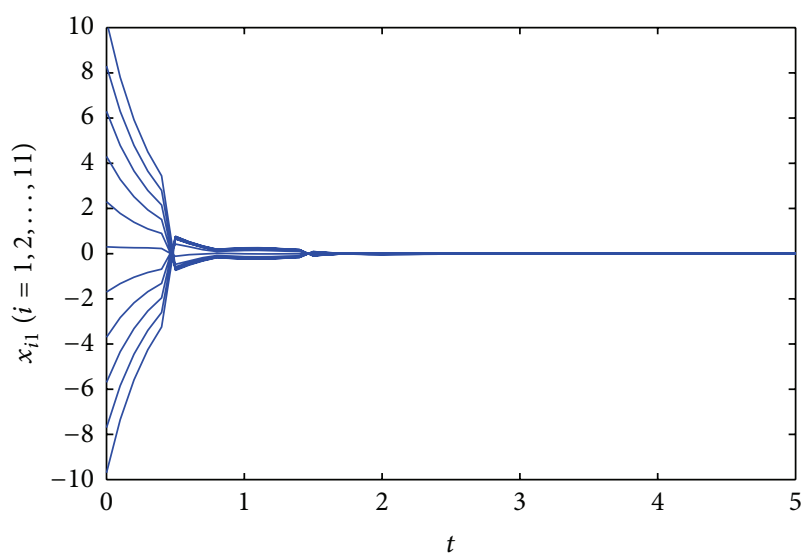

FIgURE 2: Time response of the state variable $x_{1}(t)$ with impulsive effects.

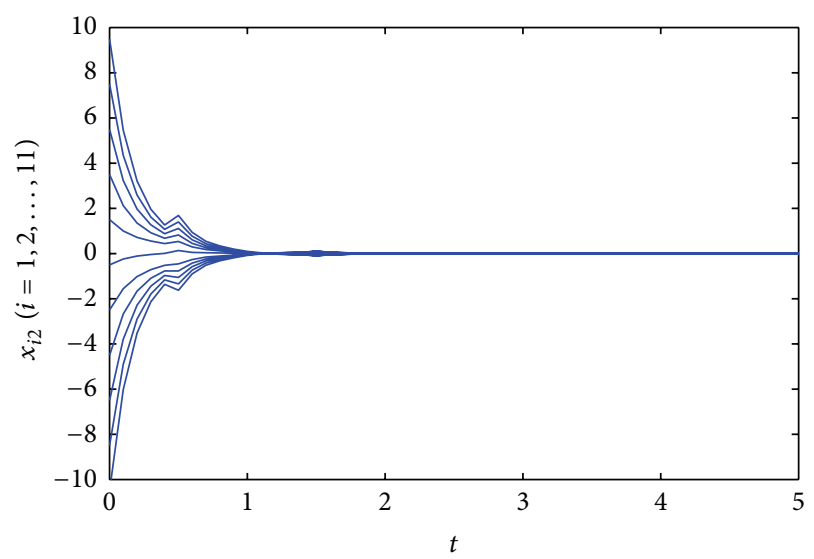

FIGURE 3: Time response of the state variable $x_{2}(t)$ with impulsive effects.

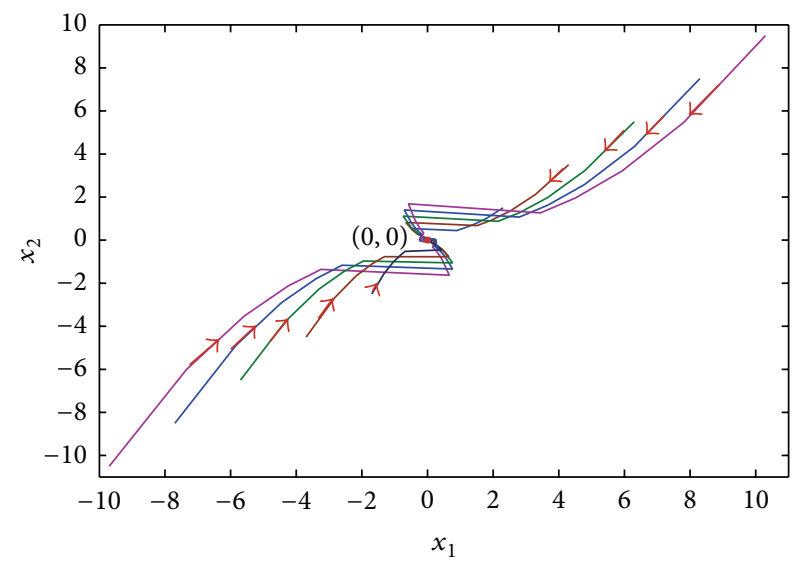

FIGURE 4: Time response of the state variables $x_{1}(t)$ and $x_{2}(t)$ with different initial conditions.

\section{Competing Interests}

The authors declare that they have no competing interests. 


\section{Acknowledgments}

This work was supported by National Natural Science Foundation of China (Grants nos. 61473244, 61563048, and 11402223), Specialized Research Fund for the Doctoral Program of Higher Education (Grant no. 20136501120001), Natural Science Foundation of Xinjiang (Grant no. 2014211B002), Natural Science Foundation of Xinjiang University (Grant no. BS130108), and Project Funded by China Postdoctoral Science Foundation (Grant no. 2013M540782 and no. 2014T70953).

\section{References}

[1] M. A. Cohen and S. Grossberg, "Absolute stability of global pattern formation and parallel memory storage by competitive neural networks," IEEE Transactions on Systems, Man, and Cybernetics, vol. 13, no. 5, pp. 815-826, 1983.

[2] Q. Song and J. Zhang, "Global exponential stability of impulsive Cohen-Grossberg neural network with time-varying delays," Nonlinear Analysis: Real World Applications, vol. 9, no. 2, pp. 500-510, 2008.

[3] X. Yang, "Existence and global exponential stability of periodic solution for Cohen-Grossberg shunting inhibitory cellular neural networks with delays and impulses," Neurocomputing, vol. 72, no. 10-12, pp. 2219-2226, 2009.

[4] C. Li, Y. Li, and Y. Ye, "Exponential stability of fuzzy CohenGrossberg neural networks with time delays and impulsive effects," Communications in Nonlinear Science and Numerical Simulation, vol. 15, no. 11, pp. 3599-3606, 2010.

[5] H. J. Chang, C. H. Moog, A. Astolfi, and P. S. Rivadeneira, "A control systems analysis of HIV prevention model using impulsive input," Biomedical Signal Processing and Control, vol. 13, no. 1, pp. 123-131, 2014.

[6] Y. Xie, Z. Yuan, and L. Wang, "Dynamic analysis of pest control model with population dispersal in two patches and impulsive effect," Journal of Computational Science, vol. 5, no. 5, pp. 685695, 2014.

[7] T. Yang, Impulsive Control Theory, vol. 272 of Lecture Notes in Control and Information Sciences, Springer, Berlin, Germany, 2001.

[8] S. Chen, Q. Yang, and C. Wang, "Impulsive control and synchronization of unified chaotic system," Chaos, Solitons \& Fractals, vol. 20, no. 4, pp. 751-758, 2004.

[9] T. Yang, L.-B. Yang, and C.-M. Yang, "Impulsive control of Lorenz system," Physica D. Nonlinear Phenomena, vol. 110, no. 1-2, pp. 18-24, 1997.

[10] T. Yang, "Impulsive control," IEEE Transactions on Automatic Control, vol. 44, no. 5, pp. 1081-1083, 1999.

[11] C. Li, W. Yu, and T. Huang, "Impulsive synchronization schemes of stochastic complex networks with switching topology: average time approach," Neural Networks, vol. 54, pp. 85-94, 2014.

[12] C. Li, C. Li, and T. Huang, "Exponential stability of impulsive high-order Hopfield-type neural networks with delays and reaction-diffusion," International Journal of Computer Mathematics, vol. 88, no. 15, pp. 3150-3162, 2011.

[13] C. Hu, H. Jiang, and Z. Teng, "Globally exponential stability for delayed neural networks under impulsive control," Neural Processing Letters, vol. 31, no. 2, pp. 105-127, 2010.

[14] Q. Zhang, X. Wei, and J. Xu, "On global exponential stability of delayed cellular neural networks with time-varying delays,"
Applied Mathematics and Computation, vol. 162, no. 2, pp. 679686, 2005.

[15] Q. Zhang, X. Wei, and J. Xu, "Global exponential convergence analysis of delayed neural networks with time-varying delays," Physics Letters A, vol. 318, no. 6, pp. 537-544, 2003.

[16] S. Ahmad and I. M. Stamova, "Global exponential stability for impulsive cellular neural networks with time-varying delays," Nonlinear Analysis: Theory, Methods \& Applications, vol. 69, no. 3, pp. 786-795, 2008.

[17] X. Wang, C. Li, T. Huang, and X. Pan, "Impulsive control and synchronization of nonlinear system with impulse time window," Nonlinear Dynamics, vol. 78, no. 4, pp. 2837-2845, 2014.

[18] X. Wang, J. Yu, C. Li, H. Wang, T. Huang, and J. Huang, "Robust stability of stochastic fuzzy delayed neural networks with impulsive time window," Neural Networks, vol. 67, pp. 84-91, 2015.

[19] S. Mohamad, "Exponential stability in Hopfield-type neural networks with impulses," Chaos, Solitons and Fractals, vol. 32, no. 2, pp. 456-467, 2007.

[20] L. Zhang, "Stability in impulsive bi-directional associative memory neural networks with time-varying delays," International Mathematical Forum, vol. 4, no. 29-32, pp. 1419-1441, 2009.

[21] Z. Gui and W. Ge, "Existence and uniqueness of periodic solutions of nonautonomous cellular neural networks with impulses," Physics Letters A, vol. 354, no. 1-2, pp. 84-94, 2006.

[22] Y. Xia, J. Cao, and S. Cheng, "Global exponential stability of delayed cellular neural networks with impulses," Neurocomputing, vol. 70, no. 13-15, pp. 2495-2501, 2007.

[23] D. Yang, G. Qiu, and C. Li, "Global exponential stability of memristive neural networks with impulse time window and time-varying delays," Neurocomputing, vol. 171, pp. 1021-1026, 2015.

[24] A. Abdurahman and H. Jiang, "The existence and stability of the anti-periodic solution for delayed Cohen-Grossberg neural networks with impulsive effects," Neurocomputing, vol. 149, pp. 22-28, 2015.

[25] H. Kang, X. Fu, and Z. Sun, "Global exponential stability of periodic solutions for impulsive Cohen-Grossberg neural networks with delays," Applied Mathematical Modelling, vol. 39, no. 5-6, pp. 1526-1535, 2015. 


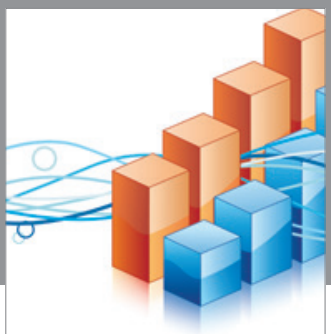

Advances in

Operations Research

vatem alat4

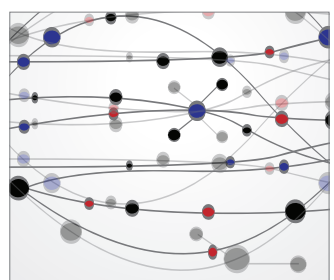

\section{The Scientific} World Journal
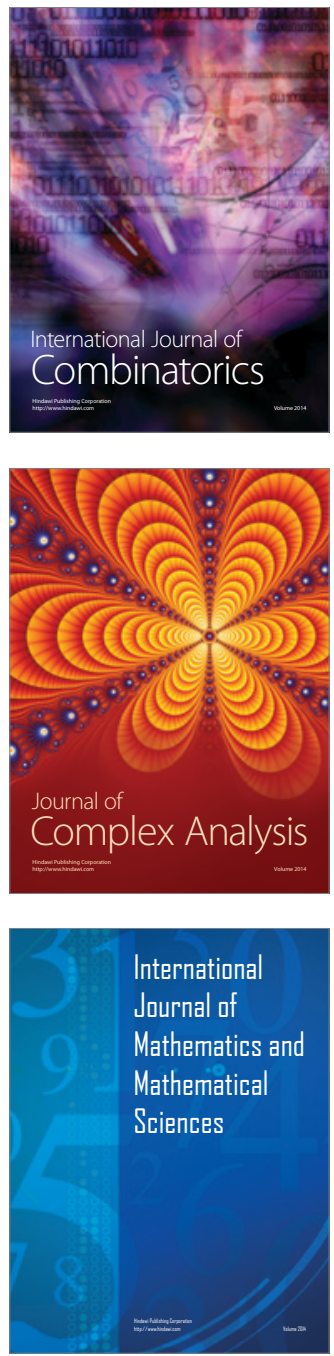
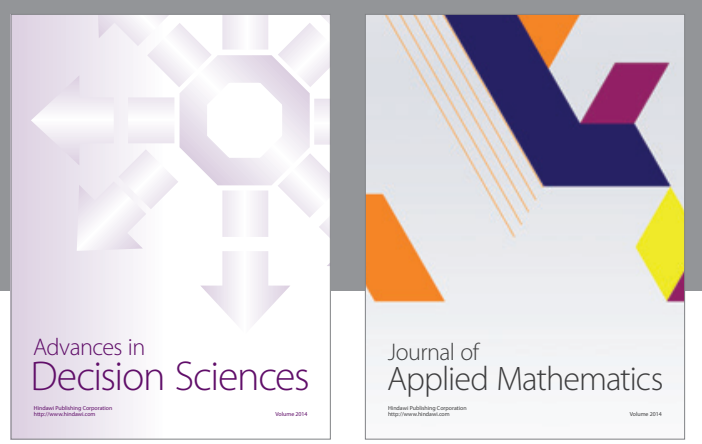

Algebra

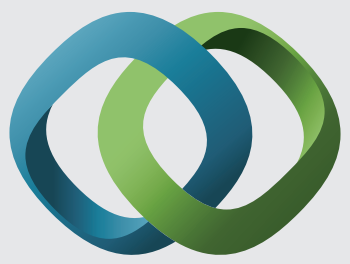

\section{Hindawi}

Submit your manuscripts at

http://www.hindawi.com
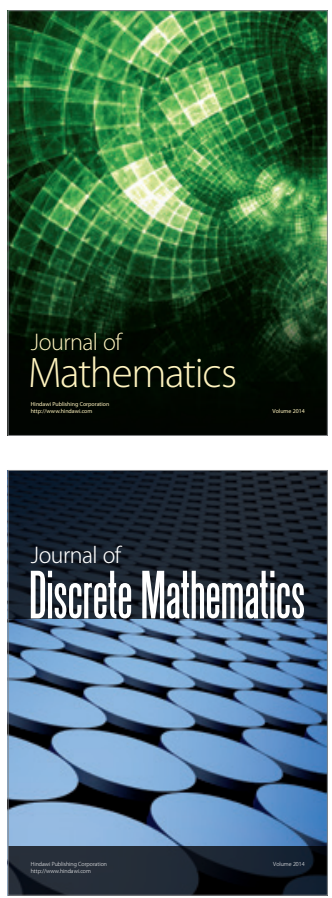

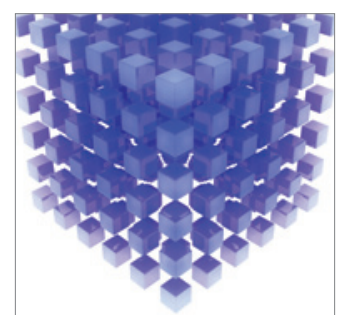

Mathematical Problems in Engineering
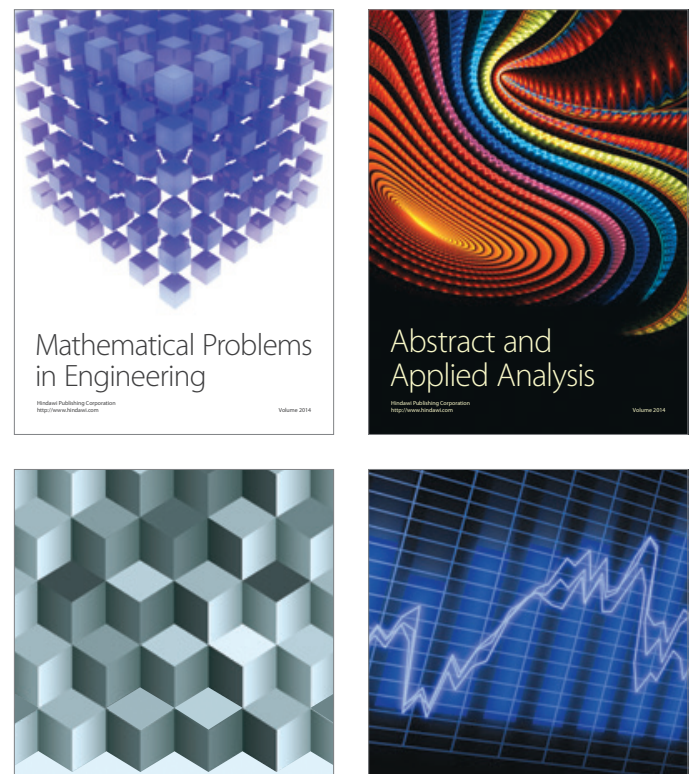

Journal of

Function Spaces

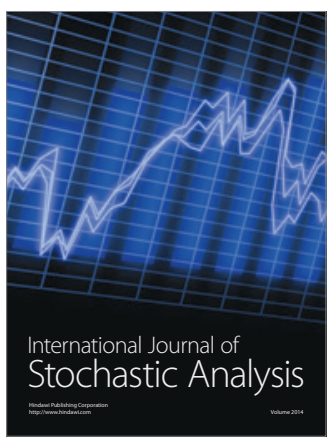

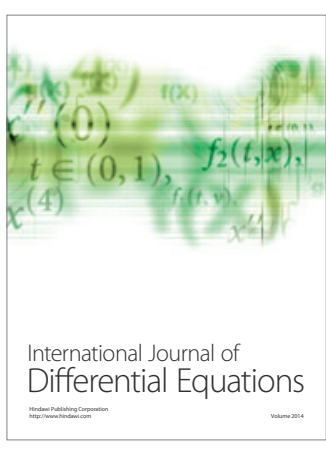
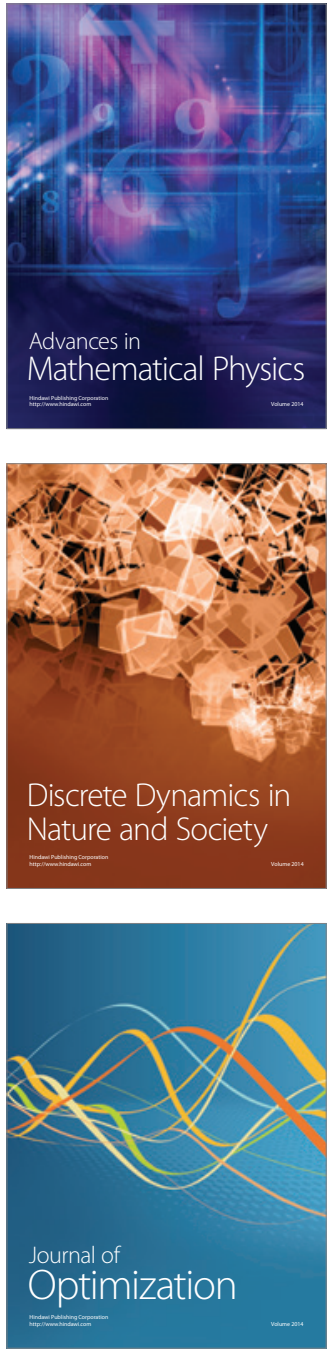